\title{
EFICÁCIA PROBATÓRIA DO COMPORTAMENTO DAS PARTES
}

\begin{abstract}
IVAN RIGHI*
SUMÁRIO: 1. Introdução. 2. Fato jurídico processual. 3. A conduta das partes como fato jurídico processual. 4. Eficácia probatória do comportamento das partes. 5. Conceito de comportamento das partes. 6 . Indícios e presunções. 7. Classificação dos indícios. 8. Conduta omissiva. 9. Conduta comissiva. 10. Modo de conduzir a causa. 11. Conduta do advogado. 12. Admissão dos fatos. 13. Valor probante. 14. Fundamentação do pronunciamento decisório.
\end{abstract}

1. Tenho o propósito de indagar como a conduta processual das partes contribui para a formação do convencimento do juiz. Despertou-me a atenção para o tema a leitura da tese de láurea escrita em 1965 por Giorgetta Somogyi, discípula de Liebman, sob o título "Eficácia Probatória do Comportamento das Partes no Processo Civil de Conhecimento".

Somogyi, por sua vez, inspirou-se no texto do art. 116 do Código de Processo Civil italiano, de 1940, que tem a seguinte redação: "O juiz pode extrair argumentos de prova das respostas das partes ao interrogatório informal, da recusa injustificada em consentir as inspeções ordenadas e, em geral, do comportamento que mantenham no processo".

Sobre a matéria, examinei o trabalho denominado "Comportamento Processual das Partes e Convicção do Juiz", que Gino Gorla publicou na "Revista di diritto processuale", em 1935 - vigente, portanto, o Código de Processo Civil italiano, de 1865 , que não continha preceito genérico sobre as conseqüências probatórias do comportamento das partes. Repassei alguns trechos da "Prova Civil", de Carnelutti, e consultei os

*) Professor-Adjunto de Direito Processual Civil. na Universidade Federal do Paraná, e Juiz do Tribunal de Alçada. 
seguintes artigos divulgados pela citada revista de Direito Processual: "Conseqüências da Falta de Exibição de Documentos em Juízo" (Calamandrei, 1930) e "O Valor Jurídico das Admissões do Procurador" (Betti, 1924). Além disso, preocupei-me apenas com a legislação.

2. O desenvolvimento do tema pressupõe a formulação do conceito de fato jurídico processual.

Ninguém desconhece que o ato processual é espécie do ato jurídico em geral. Caracteriza-se pela incidência sobre a relação processual, ou, mais propriamente, pela produção de efeitos no processo - que, através dele, tem início, movimentação e encerramento. Representa, por outro aspecto, acontecimento dependente da vontade dos sujeitos processuais, entrando em cena, pois, o elemento da voluntariedade.

Fato jurídico processual, a seu turno, é o acontecimento que independe da vontade das pessoas e se apresenta dotado de revelância para o processo. Assim, por exemplo, a morte da parte, que suspende o feito, e o motivo de força maior, quando autorize a devolução de prazo perdido.

Importa assinalar que 0 ato processual é, também, fato processual. Em verdade, além da noção comum de que o fato jurídico, no sentido amplo, é o gênero de que são espécies o ato jurídico e o fato jurídico "stricto sensu", não se deve esquecer que algumas figuras mostram-se "suscetíveis de entrada em mais de uma classe" - surgindo, então, o ato-fato jurídico, a que se refere Pontes de Miranda, no "Tratado de Direito Privado".

Em outras palavras, é possível que o ato processual produza efeitos como ato jurídico. Servem de exemplo os efeitos secundários da sentença, que ela não produz como ato de equacionamento da lide e, sim, na sua condição de fato processual relevante, do qual a lei extrai conseqüências jurídicas. É desse modo que a sentença criminal condenatória torna certa a obrigação de indenizar o dano decorrente do delito.

3. O comportamento das partes, revelado através dos atos que praticam e das atividades que omitem no curso do processo, é fato jurídico que pode apresentar relevância probatória ${ }^{1}$.

1. A confissão não é conseqüência probatória da conduta da parte (fato processual), mas, sim, o próprio ato (dispositivo) de produção da prova. Vale o inverso, porém, quanto à denominada confissão ficta. 
A própria lei, ao estabelecer presunções, extrai eficácia probatória da conduta da parte ${ }^{2}$. Assim, a aceitação da veracidade dos fatos alegados pela parte contrária, nas hipóteses de revelia (art. 319) e negativa de exibição de documento (ar. 359). No mesmo sentido, a suposição de autenticidade da assinatura e veracidade do contexto de documento particular não impugnado (art. 372), mais ainda a confissão ficta resultante da falta de comparecimento - ou da recusa a depor — da parte intimada a prestar depoimento pessoal (art. 343, § 2..$^{\text {). }}$.

Outras vezes, o legislador, ao invés de estabelecer a presunção, autoriza que o magistrado a formule, no caso concreto, extraindo da conduta processual das partes argumentos de prova para a decisão da lide ${ }^{3}$. Encontra-se exemplo desta espécie no art. 345 do Código de Processo Civil: "Quando a parte, sem motivo justificado, deixar de responder ao que lhe for perguntado ou empregar evasivas, o juiz, apreciando as demais circunstâncias e elementos de prova, declarará, na sentença, se houve recusa de depor".

4. A eficácia probatória do comportamento das partes, entretanto, independe de prevịão legal. Basta, apenas, reconhecer - como o legislador o fez, nos casos anteriormente apontados - a natureza de fonte de presunções à conduta processual das partes ${ }^{4}$.

Bem por esse motivo, aliás, aceitava-se a referida eficácia ao tempo do Código de Processo italiano de $1865^{5}$, cuja omissão no tratamento da matéria se repete no correspondente diploma brasileiro em vigor.

Na realidade, a eficácia ora analisada subordina-se; apenas, à circunstância de que a legislação processual não repila o princípio da convicção racional do juiz na valoração da prova ${ }^{6}$. Gior-

2. Aliás, mesmo fora do terreno probatório, são inúmeras as consequêencias processuais que a lei faz derivar do comportamento das partes. Basta referir, porque muito expressiva, a preclusão temporal (art. 183) .

3. Gino Gorla, ob. cit., pág. 40, fala de "autorizzazione legislativa alla presunzione".

4. Gino Gorla, ob. cit.. pág. 27, adotando a linguagem de Carnelutti, diz "fonte di presunzione" - isso significa que o juiz, a partir de evidência constante dos autos, pode chegar a uma presunção simples. Castro Mendes, "Do conceito de Prova em Processo Civil", pág. 178, refere-se a "fatos probatórios" e os define como sendo aqueles cuja demonstração permite concluir pela verdade ou falsidade de um fato principal (este entendido como o que "condiciona diretamente a decisão") .

5. Gino Gorla, ob. cit., pág. 25, e autores referidos por Calamandrei, ob. cit., pág. 299, nota 2.

6. A conclusão é de Gino Gorla ob. cit., pág. 27. 
getta Somogyi, com efeito, assevera que os argumentos de prova dessumíveis da conduta das partes incluem-se no rol dos elementos de convicção racionalmente valoráveis.

O Código de Processo Civil recepciona o princípio da valoração racional da prova (art. 131) e, além disso, dispõe que todos os meios legais ou moralmente legítimos são hábeis à demonstração "da verdade dos fatos. em que se funda a ação ou a defesa" (art. 332). Indiscutívelmente, portanto, no direito brasileiro, a conduta processual das partes é fator produtivo de conseqüências probatórias.

5. "Comportamento significa modo de agir. Assim, comportamento processual é o modo de agir em juízo"7.

Não, porém, a elegância no trato ou a falta de educação, a simpatia ou a antipatia, etc. - neste sentido, nem o pior comportamento possível justifica a sentença desfavorável ${ }^{8}$. Gino Gorla, contudo, observa que a influência psicológica ou atmosfera criada por essas impressões costuma produzir erros judiciários.

Interessa, isto sim, o comportamento processual que permite ilações racionais, de conteúdo probatório, úteis para a decisão da lide. Vale dizer, a conduta que - encarada pelo juiz como fato processual - sirva de indício e propicie, mediante o emprego de critério lógico-dedutivo, uma conclusão acerca de questão importante ao equacionamento do litígio.

6. Ninguém desconhece que os fatos principais para 0 julgamento da lide podem ser inferidos a partir de fatos secundários, aos quais se relacionem. É a prova crítica, ou circunstancial, que se obtém pela conjugação do fato secundário conhecido às "regras de experiência comum subministradas pela observação do que ordinariamente acontece"'.

Nessa operação, enquanto o fato secundário denomina-se indício, o resultado a que se chega corresponde a uma presunção. O Código de Napoleão, a esse respeito, dispunha: "presun-

7. Gino Gorla, ob. cit., pág. 24 .

8. Conforme Ricca-Barberis, mencionado por Giorgetta Somogyi, ob. cit., pág. 24. Sequer a conduta maliciosa da parte, acrescenta o referido jurista, autoriza julgamento divorciado da prova produzida a respeito dos fatos da causa. O comportamento desleal, de má-fé ou atentatório à dignidade da Justiça, entretanto, acarreta sérias conseqüências, embora não de ordem probatória (arts. 16, 18, 22, 113 e $\S 1.0^{\circ}, 601$, "verbi gratia") .

9. Código de Processo Civil, art. 335. 
ções são as conseqüências que a lei ou o homem tira de um fato conhecido para provar a existência de outro desconhecido".

A operação referida, por outro aspecto, amolda-se à figura do silogismo: a) premissa menor é o fato secundário conhecido; b) maior, a regra de experiência aplicável; c) conclusão, a presunção sobre o fato principal ignorado.

Presunção, portanto, é o resultado de uma operação lógica que tem ponto de partida no indício. Este, a seu turno, pode ser um fato processual: o comportamento das partes.

7. Gino Gorla, referindo-se aos indícios como fontes de presunções, explica que admitem a seguinte distinção: a) extraprocessuais, correspondentes aos fatos de que o juiz toma conhecimento através de iniciativa probatória sua ou das partes - as impressões digitais do suspeito, no local do crime, "verbi gratia"; b) processuais, correspondentes aos fatos de que o juiz se apercebe sem contar com a mencionada iniciativa, pois surgem no processo em virtude do comportamento das partes.

$\mathrm{Na}$ mesma linha de raciocínio, Giorgetta Somogyi assevera que a característica da eficácia probatória da conduta das partes reside na natureza processual do fato em que se apoia a operação lógica que conduz à presunção.

8. Muitas vezes, o raciocínio lógico é efetuado em abstrato pelo próprio legislador, que define, antecipadamente, a eficácia probatória de determinado comportamento processual das partes, estabelecendo presunções legais ${ }^{10}$. Assim, por exemplo, o efeito probatório da revelia, previsto no art. 319 do Código de Processo Civil, baseia-se na seguinte máxima de experiência: quem cala, consente ${ }^{11}$.

Quando a dedução lógica é efetuada pelo juiz, no caso concreto, adentra-se no terreno das presunções simples. À guisa de ilustração, seguem-se alguns exemplos: a) o réu, limitandose a alegar a compensação, admite o crédito do autor; b) solicitando prazo para a purgação da mora, fica inibido de contestar

10. Veja-se o n.०3.

11. No mesmo sentido, justifica-se a presunção estabelecida pelo art. 359 do Código de Processo Civil: "quando a parte nega-se a exibir documentos que estão em seu poder, é nautral supor que a recusa tenha o propósito de evitar a produção de prova favorável ao litigante adversário" (Calamandrei, ob. cit., pág. 296). 
a ação de despejo que tem como "causa petendi" a impontualidade no pagamento do aluguel ${ }^{12}$; c) requerendo a extinção do processo sem o julgamento da lide, revela desinteresse pela sentença de mérito e não pode opor-se ao pedido de desistência formulado pelo autor; d) a parte que não se submete à inspeção judicial, ou deixa de praticar ato que lhe é determinado ${ }^{13}$, suporta o risco de que tal atitude evidencie descumprimento da ordem com o propósito de não produzir prova em favor do litigante adversário.

9. É, quase sempre, do comportamento omissivo da parte que a lei e o juiz extraem conseqüências probatórias. $\mathrm{O}$ comportamento comissivo, entretanto, também pode fornecer o indício que serve de base à presunção ${ }^{14}$.

Suponha-se a subtração, ou inutilização, de documento constante dos autos do processo, por uma das partes litigantes. Temse ato-fato processual, que admite o seguinte desdobramento: a) crime contra a Administração Pública ${ }^{15}$; b) indício que favorece, com apoio na experiência comum, ou seja, considerando-se "quod plerumque fit", a presunção de que o documento fazia prova em benefício da parte adversária.

10. Os argumentos de prova, por outro aspecto, tanto podem resultar do comportamento da parte correlacionado a um ato processual específico, quanto de seu modo de atuação em juízo durante o procedimento inteiro, ou cada uma das fases que o compõem. Basta pensar na intenção protelatória revelada pela parte ao longo da tramitação do processo, ou na proposição de meios de prova para a demonstração de fatos incompatíveis com os precedentemente alegados ${ }^{16}$.

Nessa perspectiva, como bem assinala Giorgetta Somogyi, a atividade da parte mostra-se "indissoluvelmente conexa à do próprio defensor". Em outras palavras, o comportamento da parte

12. Note-se que a eficácia probatória da conduta das partes confunde-se, algumas vezes, com a preclusão lógica.

13. Código de Processo Civil, art. 340, I e Ir.

14. Cogita-se mais freqüentemente, diz Giorgetta Somogyi, ob. cit. pág. 42, "do comportamento negativo das partes. Deve-se ter em conta, porém, todos os aspectos da conduta das partes no processo". A seguir, acrescenta que a proposição de um meio de prova, analisada como manifestação do comportamento da parte, desempenha, algumas vezes, o papel de fonte de presunção".

15. Código Penal, art. 337. Se o sujeito ativo for advogado, e nesta condição tiver recebido o documento, configurar-se-á o delito previsto no art. 356 (Fragoso, "Lições", 3.a ed., Parte Especial, III, 501) .

16. Exemplos formados por Giorgetta Somogyi, ob. cit., pág. 37 . 
é analisado sob ângulo do "modo de conduzir a causa"17 — tarefa que cabe ao advogado.

11. Não é possível negar que o Código de Processo Civil, quando faz referência às partes, abrange, também, os advogados que as representam em juízo - e, raramente, aparecem como figuras autônomas no curso do procedimento. Em verdade, sempre que o legislador quer empregar o aludido vocábulo no sentido restrito, a fim de excluir o advogado, qualifica-o da seguinte maneira: parte, pessoalmente ${ }^{18}$.

São bem poucos, aliás, os atos do processo em que a parte intervem diretamente: o normal é que desenvolva através de seu advogado a atividade processual que lhe cabe. Assim, é evidente que a conduta processual do advogado - "rectius", o modo pelo qual ele conduz a causa - pode ocasionar prejuízo à parte ${ }^{19}$.

Não se trata de eficácia jurídica decorrente do princípio da representação, pois o advogado tem o poder de sustentar em juizo, com autonomia, o interesse do cliente, mas, não, o de dispor do mesmo ${ }^{20}$. A parte suporta o efeito da má condução da causa pelo advogado, isto sim, como conseqüência de ordem prática, ou, na explicação fornecida por Gino Gorla, em virtude do "princípio da responsabilidade pela escolha do defensor".

A esse respeito, é bom lembrar que James Goldschmidt definia o processo como verdadeiro jogo, sujeito, quanto ao resultado, à sagacidade e diligência das partes e seus procuradores. O próprio Calamandrei, crítico da teoria do processo como situação jurídica, reconheceu-lhe o aspecto de "concepção realística" ${ }^{21}$ e, depois, escreveu, no "Elogio dei giudici", a seguinte historieta: "O cliente não sabe que, muitas vezes, depois da vitória, deveria abraçar comovido não o seu advogado, mas, sim, o defensor da parte contrária".

Também ao legislador português não passou desapercebida a influência do advogado no fiel da balança da Justiça, como se infere do disposto no Livro III, Título XX, das Ordenações Fili-

17. Gino Gorla, ob. cit., pág. 24 .

18. A observação, feita por Giorgetta Somogyi, ob. cit. pág. 46, nota n.० 1, aplica-se ao direito brasileiro. Vejam-se, por exemplo, os arts. 267 , $\S 1 .^{\circ}$, e 342 do Código de Processo Civil.

19. Na hípótese do art. 453, § 2..$^{\circ}$ contudo, é efetivamente da conduta do advogado que o Código de ŕrocesso Civil autoriza o juiz a deduzir argumentos de prova.

20. Gino Gorla, ob. cit., pág. 30, e Betti, ob. cit., pág. 196.

21. "Il processo come situazione giuridica", "Rivista di diritto processuale", 1927, I, pág. 225. 
pinas: "Mandamos, que se dois procuradores mais avantajados forem na Corte, e uma parte tomar ambos, não lhe seja consentido, mas escolha um deles e deixe o outro ao seu adversário, se o quis... E isto se fará geralmente em todos os feitos, de qualquer substância que sejam, para que as partes não percam seu direito por desigualdade dos procuradores".

12. O Código de Processo Civil confere relevância probatória à falta de impugnação especificada dos fatos, de tal sorte que os não controversos presumem-se admitidos e dispensam 0 ônus da prova ${ }^{22}$.

Quem admite o fato, porém, não é a parte, mas o advogado, e isso na medida em que oferece "conclusões acordes com as do litigante adversário ${ }^{23}$. Logo, a admissão não se identifica à confissão, que é ato dispositivo da parte, em matéria de fato ${ }^{24}$.

A admissão, sob outro prisma, não se destina a produzir prova, pois, é inadmissível que o advogado "prejudique o cliente com declarações dispositivas"25. Trata-se de simples falta de combate às alegações da parte contrária e proporciona o indício de que se vale o legislador, apoiado na experiência comum de ser verdadeiro o que não foi contradito, para a dispensa do ônus da prova ${ }^{26}$.

13. A prova crítica, em princípio, é menos valiosa do que a prova direta dos fatos principais. Nada impede, todavia, que a robusteça, atuando como demostração complementar e influindo na sua valoração. Em outros termos, é possível que o indício apresente-se como "circunstância qualificadora", capaz de ultimar a fixação de outra prova ${ }^{27}$.

Atento a essa particularidade, Gino Gorla assevera que "o comportamento processual das partes pode ser elemento de

22. Arts. 302 e 334 , III.

23. Betti, ob. cit., pág. 196 .

24. Veja-se a observação constante da nota n. ${ }^{1}$.

25. Betti, ob. cit., pág. 197.

26. Castro Mendes, ob. cit.. págs. 447 e 551, sustenta que a admissão funciona "como mera omissão de um possivel fato impeditivo do valor probatório da alegação" da parte contrária, e resulta normalmente da circunstância “de o admitente julgar que ela não o prejudica”. Betti, ob. cit., págs. 203 e 204, levando em conta o direito italiano, assinala que o indício decorrente da admissão do fato serve de base a que o juiz, no caso concreto, formule a conclusão adequada. No Brasil, porém, a presunção é estabelecida, em abstrato, pelo próprio legislador.

27. Carnelutti, ob. cit., 1915, pág. 240. Assim como o documento pode confirmar o depoimento, ou vice-versa, o indício é capaz de acentuar o valor da prova documental ou testemunhal. 
avaliação da prova"'-28 . A essa orientação aderiu a "Corte d'AppelIo" de Florença, ao decidir que "a conduta das partes pode reforçar o convencimento do juiz sobre determinado fato, integrando-se aos outros elementos de prova constantes dos autos do processo"' 29 .

Sob aspecto diverso, inexiste motivo razoável a impedir que o comportamento das partes, como fonte de presunções, desempenhe papel predominante na composição da lide - ou, mesmo, exclusivo, à falta de outras provas ${ }^{* 0}$. Aliás, diante do que dispõe o art. 131 do Código de Processo Civil, outra conclusão seria inadmissível. Há de se exigir, porém, univocidade dos indícios e segurança na presunção.

A eficácia probatória da conduta das partes concorre, tanıbém, para o equacionamento de questões meramente processuais. Giorgetta Somogyi menciona o indeferimento da produção de provas e indica precedentes da Corte de Cassação italiana ${ }^{31}$.

14. Em se tratando de presunções simples, é indispensável que o juiz revele, na fundamentação do pronunciamento decisório, o raciocínio que o levou a extrair conseqüências probatórias do comportamento das partes. Sem isso, com efeito, não será possível o controle da operação lógica efetuada.

Quanto às presunções legais, a fundamentação é de rigor a fim de que o juiz as repila. Tais presunções, embora dispensem do ônus da prova quem as tem a seu favor:32, geralmente são "juris tantum" e, por conseguinte, cedem à evidência em contrário.

28. E prossegue: "Da conduta das partes, o juiz, muitas vezes (e, algumas, quase inconscientemente), tira argumentos para a valoração da prova. "Verbi gratia", a convicção do juiz sobre a falsidade ou veracidade do depoimento da testemunha pode ser determinada pelo comportamento processual das partes" (ob. cit., págs. 26 e 28 ).

29. Acórdão referido por Giorgetta Somogyi, ob. cit., págs. 81 e 82 .

23. Giorgetta Somogy, ob. cit., págs. 85 e 88 , esclarece que a jurisprudência Italiana admite, embora com parcimônia, que o juiz apoie a sentença, prevalentemente, nos argumentos de prova extraídos da conduta das partes.

31. Ob. Cit., pág. 37. Pode-se acrescentar, "verbi gratia", a hipótese de extinçāo do processo que "ficar parado durante mais de um ano por negligîncia das partes" (Código de Processo Civil, art. 267, II, e § 1.0). Trata-se de presunção legal de que não há interesse no prosseguimento do feito.

32. Código de Processo Civil, art. 334, IV. 